\title{
BIOSLURPING - HORIZONTAL RADIAL FLOW - THEORY AND EXPERIMENTAL VALIDATION
}

\author{
${ }^{1}$ S.S. Di Julio and ${ }^{1}$ W.H. Shallenberger \\ ${ }^{1}$ Mechanical Engineering Department, California State University, Northridge, 18111 \\ Nordhoff St., Northridge, CA 91330-8348; Phone: (818)677-2496; Fax: (818)677-7062; \\ sdijulio@ecs.csun.edu; billshall@juno.com.
}

\section{ABSTRACT}

Two-dimensional (2-D) analytical equations to describe horizontal radial flow (HRF) have been developed. An HRF test cell has been designed and fabricated. Measurements of flow rate and pressure vs. radius were compared with theoretical values derived. Reasonable agreement between measurements and theory validated the analytical equations derived. These equations can form a basis for the field study of the remediation process known as "bioslurping," used for removal of light nonaqueous-phase liquid (LNAPL).

Key words: bioslurping, free product recovery, multiphase recovery, bioventing, horizontal radial flow

\section{INTRODUCTION}

Bioslurping is a technique recently used by the U.S. government to remove light nonaqueousphase liquid (LNAPL) from contaminated sites (Kittel et al., 1994; De Vantier and Hoeppel, 1996). Examples of LNAPL are jet fuel and diesel fuel. Because the volume of contamination is usually very large (in tens of thousands of gallons), a layer of this hydrocarbon contamination exists as a free product above the groundwater, as well as in the capillary fringes (Hoeppel et al., 1991). At the contaminated site used in this study, wells about four inches in diameter were drilled to the depth of the groundwater. Then an extraction tube of about one-inch in diameter was inserted into the well, located preferably at the interface of the contaminant and the water since the location of the interface can easily be identified. A vacuum was connected to the extraction tube and the contaminant removed. In situ biological remediation of the contaminant, including chlorinated solvents, was enhanced (Hoeppel et al., 1991, 1999) due to induced air flow, hence the name bioslurping was coined. Assessment of bioslurping technology at 23 Air Force sites, in comparison with other conventional remediation techniques such as skimming and dual pumping, indicated that LNAPL recovery was greater using the bioslurping technique.

In order to understand the complex fluid-flow behavior near the extraction tube, we have developed analytical equations which describe the horizontal radial-flow (HRF) behavior (Hoeppel, et al., 1996). We have also designed, fabricated, and made measurements on an HRF laboratory model, referred to as the HRF test cell throughout this paper. The purpose of the laboratory model was to simulate, in the laboratory, a field well under conditions by which pertinent parameters can be controlled and measured. Results of laboratory measurements were compared with theoretical analyses to validate theoretical equations derived here.

In general, there is good agreement between theoretical and measurement results presented as pressure vs. radius curves, but the theoretical and measurement results differ in the magnitude of the pressure gradients. In the case of air tests, the difference seems attributable to differences in permeabilities of the 


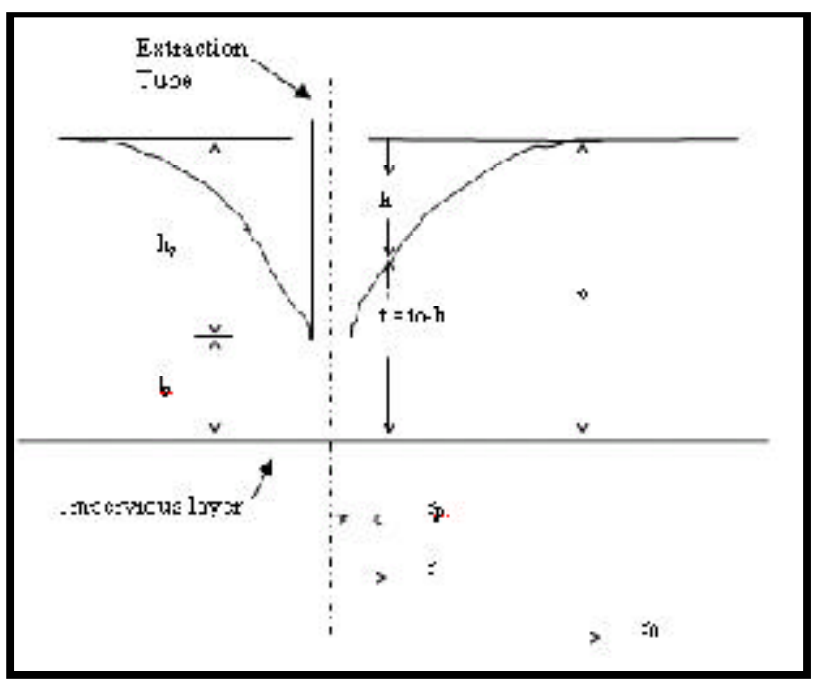

Figure 1. Liquid in open space-gravity driven.

test column (assembled to independently measure the permeability of the packing) and the HRF test cell. While in the case of water, bypassing any sand flow in the HRF test cell may be the source of discrepancy. However, in spite of the experimental problems, the theoretical equations derived can be the basis for analysis and design of a full-scale system and prediction of its performance.

\section{THEORY AND DEVELOPMENT OF EQUATIONS}

The basic equations applied to theoretical horizontal radial flow under idealized conditions are presented. To simplify, it was assumed that porous media have uniform permeability throughout, even though in soils, grain size varies widely from very fine to very coarse, causing variation in permeability. It was also assumed that the region being studied was bounded on the bottom by an impervious horizontal surface. In all cases studied, it was assumed that flow was radial from a region of infinite diameter.

\section{a. Liquid in Open Space - Gravity Driven}

This case is typical of an open body of liquid lying above a horizontal impervious surface, such as a lake or the bottom of a soda glass. A vertical extraction tube (or soda straw) was used to extract liquid, causing horizontal flow of the surrounding liquid, Figure 1. The upper surface of the liquid dipped toward the extraction pipe as the gravity head was converted to horizontal velocity of the liquid. As the liquid approached the extraction pipe, the flow area decreased with decreasing radius and with decreasing vertical thickness of the fluid. Although the upper surface of the liquid dropped with decreasing radius, it was assumed that any vertical component of flow was negligible compared to the horizontal flow. Hence, a 2-D model was sufficient to study the dominant-fluid flow characteristics. It was also assumed there was no viscous drag of liquid along the horizontal bottom surface or within the body of the liquid.

As shown in Figure 1, fluid was being extracted at such a rate that the upper surface had dropped to the level of the bottom of the extraction pipe and "slurping" (simultaneous extraction of air 
and liquid) was possible. This represented the condition for maximum liquid flow for the configuration shown. Any attempt to increase flow will result only in more and more slurping. The flow rate for this condition is as follows:

$$
\begin{gathered}
Q=A V \\
A=2 \pi r t \\
A=2 \pi r\left(t_{0}-h\right) \\
V=\sqrt{2 g h} \\
Q=2 \pi r\left(t_{0}-h\right) \sqrt{2 g h} \\
Q=2 \pi \sqrt{2 g} r t_{0}\left(h^{\frac{1}{2}}-\frac{h^{\frac{3}{2}}}{t_{0}}\right) \\
Q=2 \pi \sqrt{2 g} r_{p} t_{0}^{3 / 2}\left(\frac{h_{p}}{t_{0}}\right)^{\frac{1}{2}}\left(1-\frac{h_{p}}{t_{0}}\right)
\end{gathered}
$$

The maximum flow rate occurs when

$$
\frac{d Q}{d\left(\frac{h_{p}}{t_{0}}\right)}=0
$$

That is, when the bottom of the extraction tube is one third of the distance below the free surface, i.e. when

$$
h_{p}=\frac{1}{3} t_{0}
$$

\section{b. Liquid in Porous Medium - Gravity Driven}

This case is typical of water or other liquid in an open well bounded on the bottom by an impervious layer. If there is no extraction from the well, the liquid level in the well will be the same as that in the soil, neglecting capillary forces. If liquid is drawn from the well, the level in the well will drop, and liquid will flow by gravity from the soil into the well, as shown in Figure 2. 


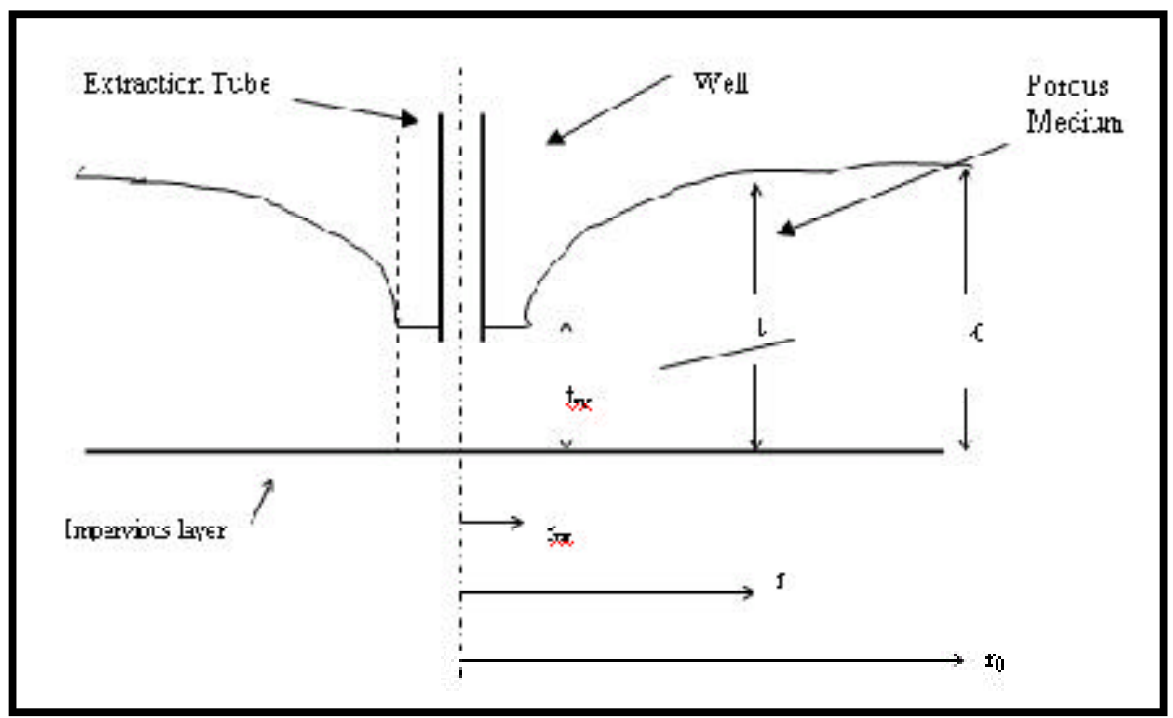

Figure 2. Liquid in porous media-gravity driven.

Gravity head overcomes the viscous force of flow in the porous medium. The basic Darcy equation is for flow through a porous medium of constant flow area. It was modified in this case to represent flow through a porous medium whose area decreased with decreasing radius and with decreasing depth of flow. The flow area at any radius is $A=2 \pi$ rt. Substituting the gravity gradient, $\rho \mathrm{gdt} / \mathrm{dr}$, for pressure gradient, $\mathrm{dp} / \mathrm{dr}$, the basic Darcy equation below is thus modified to

$$
\begin{gathered}
\frac{Q}{A}=\frac{k}{\mu} \frac{d p}{d r} \\
Q=\frac{\kappa \rho g}{\mu} 2 \pi r t \frac{d t}{d r} \\
\int_{t w}^{t} t d t=\left[\frac{Q}{2 \pi} \frac{\mu}{\kappa \rho g}\right]_{r_{w}}^{r} \frac{d r}{r} \\
Q=\frac{\pi k \rho g}{\mu}\left(t_{0}^{2}-t_{w}^{2}\right)\left[\frac{1}{\ln \frac{r_{0}}{r_{w}}}\right]
\end{gathered}
$$

\section{c. Liquid in Porous Medium - Pressure Driven}

This case represents a well driven from the ground surface into a body of liquid confined in a porous medium of thickness, t, between impervious surfaces above and below (Figure 3). The well was capped so that extraction of liquid reduced the pressure in the well, causing radial flow of liquid into the well. The basic Darcy equation for

$$
\frac{Q}{A}=-\frac{k}{\mu} \frac{d p}{d x}
$$




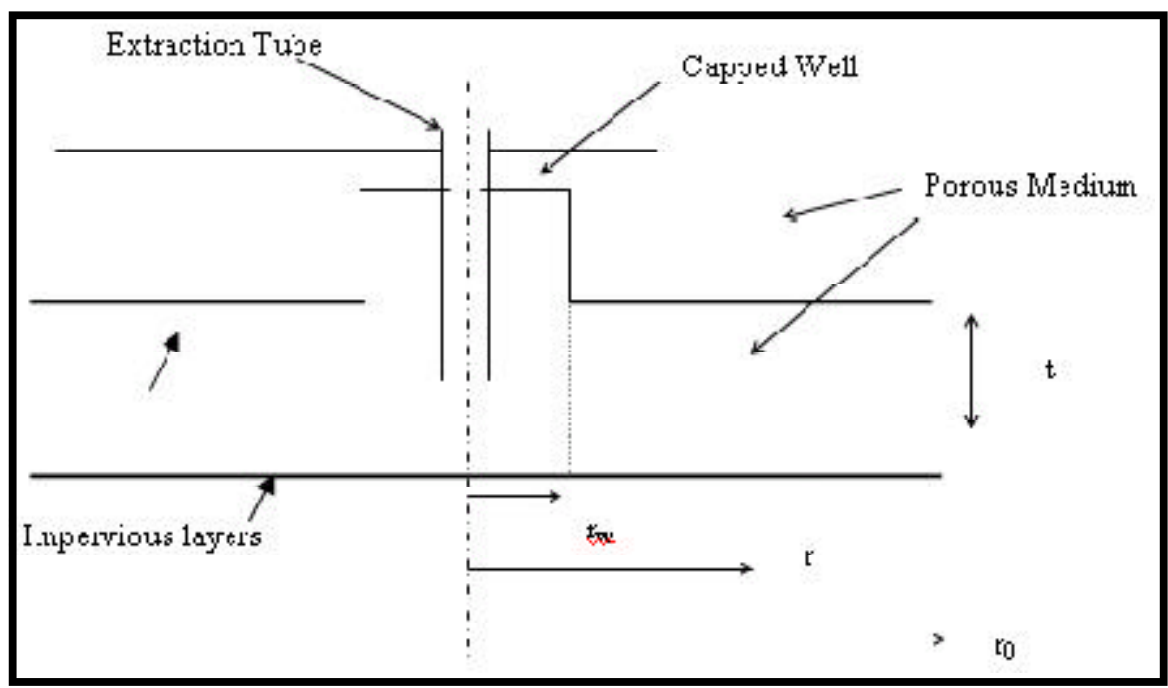

Figure 3. Liquid or gas in porous media-pressure driven.

flow through a porous medium of constant flow area was modified, since the flow area decreases with radius, $\mathrm{A}=2 \pi \mathrm{rt}$, or

$$
d p=\frac{Q}{2 \pi r t} \frac{\mu}{k} d r
$$

when integrated and rearranged

$$
Q=\frac{\frac{2 \pi t k}{\mu}}{\ln \frac{r}{r_{w}}}\left(p-p_{w}\right)
$$

The pressure gradient, $\mathrm{dp} / \mathrm{dr}$, is proportional to the flow rate, $\mathrm{Q}$, and inversely proportional to the radius, $r$. If $\mathrm{p}_{0}$ is atmospheric pressure at some distant radius, $r_{0}$, then $\left(\mathrm{p}_{0}-\mathrm{p}_{\mathrm{w}}\right)$ is the vacuum in the well and the flow rate, $\mathrm{Q}$, is proportional to that vacuum. These relations were observed in laboratory tests, whose results are described in the Results section.

\section{d. Air in Porous Medium - Pressure Driven}

In the cases of horizontal radial flow discussed above, the fluid is a liquid whose density remained constant, and Q, the volumetric flow rate, is constant. If the fluid is air, or any other gas, its specific volume increases with decreasing pressure as the gas approaches the well, shown in Figure 3. By the perfect gas equation,

$$
p Q=\dot{m} R T
$$

Temperature, T, is assumed to be constant, according to Joule's experiments of gaseous flow through a porous medium. Thus Darcy's basic equation becomes

$$
\frac{\dot{m} R T}{p(2 \pi r t)}=\frac{k}{\mu} \frac{d p}{d r}
$$




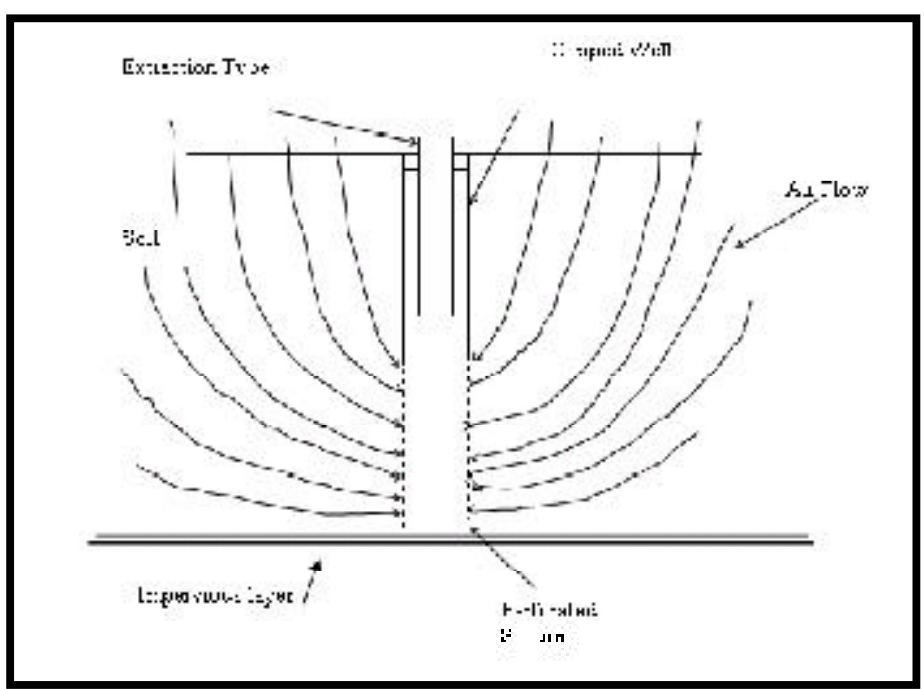

Figure 4. Three-dimensional flow of air from ground surface to well.

This rearranged integrates to

$$
\left(p^{2}-p_{w}^{2}\right)=\frac{\dot{m} R T}{\pi t} \frac{k}{\mu} \ln \frac{r}{r_{w}}
$$

Note that with liquids and gases, the flow velocity increases as a result of decreasing flow area. Additionally with gases, the flow velocity increases as a result of decreasing density. This is significant only when there is a significant difference between $\mathrm{p}_{0}$ and $\mathrm{p}_{\mathrm{w}}$ as indicated in Equation 18.

\section{e. Three-Dimensional Air Flow from Ground Surface to Well}

Figure 4 is an example of a capped well drawing air from some distance below the surface of the ground. Air entered the soil at the surface and flowed downward toward the perforated section of the well casing. Near the ground surface, the air flow was primarily vertical. Farther below the surface, there was a horizontal component as well as vertical component of flow, and at the bottom, flow was primarily horizontal.

There were no clearly defined flow boundaries, pressure distribution, or flow velocity. A mathematical solution was difficult. An electric analog model can inexpensively provide data for design of a laboratory model and even a full-scale extraction well; the analog equations are

$$
\frac{I}{A}=-\frac{1}{R} \frac{d E}{d x} \quad \frac{Q}{A}=-\frac{k}{\mu} \frac{d p}{d x}
$$

For constant thickness of fluid layer $t$, and pressures at two radii of $r_{1}$ and $r_{2}$, the horizontal radial flow of liquid was shown to be approximated as

$$
Q=2 \pi t \frac{k}{\mu}\left(p_{2}-p\right) / \ell n \frac{r_{1}}{r_{2}}
$$

The voltage distribution, which is analogous to pressure distribution, may be calculated as

$$
\Delta E=I_{360} R \frac{1}{2 \pi t} \ln \frac{r_{1}}{r_{2}}
$$




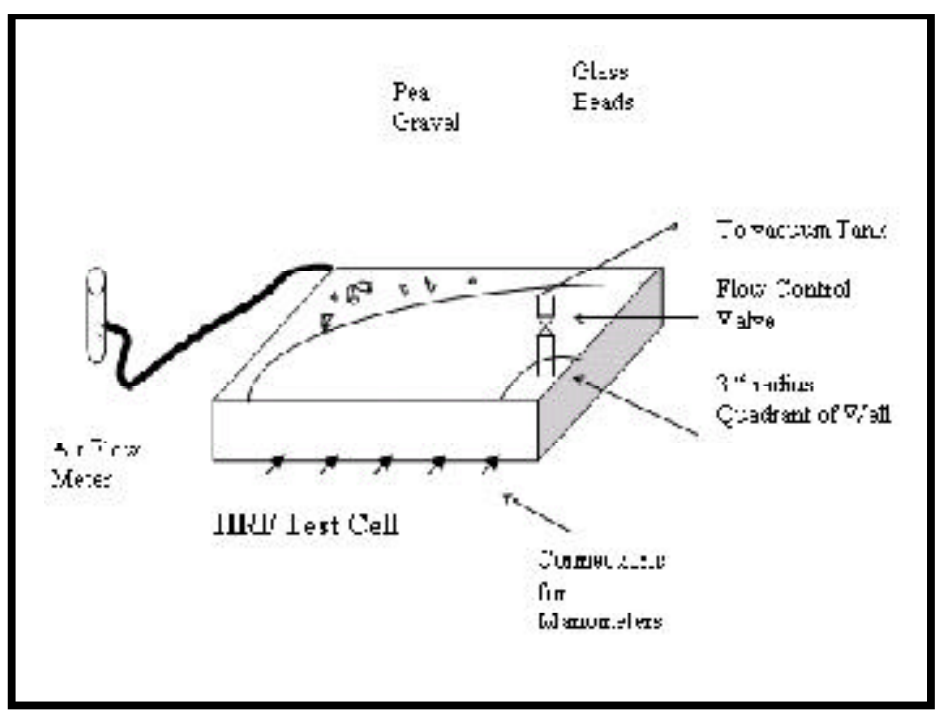

Figure 5-1. Schematics of the HRF Test Cell

\section{f. Slurping of Air and Liquid}

In the bioslurping process, there is simultaneous flow of air and liquid into the well. The flow of the liquid will be primarily horizontal, driven by both gravity and pressure gradients - a combination of flows described above in sections $b$ and $c$. The pressure at the upper liquid surface will be equal to the air pressure at that level and that radius. The flow and pressure patterns of the air will be essentially those discussed in section e, although the bottom surface for air will not be a horizontal impervious layer of soil, but rather the top surface of the liquid, which may or may not be horizontal. It is assumed that any viscous forces between the air and liquid will be small compared with the viscous forces between the fluids and the soil, and that the liquid and air can move at significantly different velocities with negligible interacting forces. Thus the two fluids can flow independently, except that the interface pressures and the elevations must be the same. It is expected that at the interface, air and liquid flows will be very nearly horizontal, except for some small gravity gradient of the liquid near the well.

The volume flow of the liquid will be approximately that determined by pressure gradients at the interface of air and liquid, assuming the well perforations are above the static level of the liquid. On the other hand, mass flow of the air will depend on how far the perforations are above the liquid level and below ground level. This will also indirectly affect the pressure at the interface. The open end of the extraction pipe must be below the free surface of the liquid; otherwise it might extract air only and no liquid. This case has not been investigated analytically or experimentally, but will be a subject for future study.

\section{TEST EQUIPMENT AND PROCEDURE}

\section{a. Horizontal Radial-Flow Test Cell}

The HRF test cell, Figure 5-1, represents one quadrant of horizontal slice of a well 6 inches in diameter out to a radius of 26 inches $(66 \mathrm{~cm})$. It consisted of a plywood tray, 30 inches $(76 \mathrm{~cm})$ 


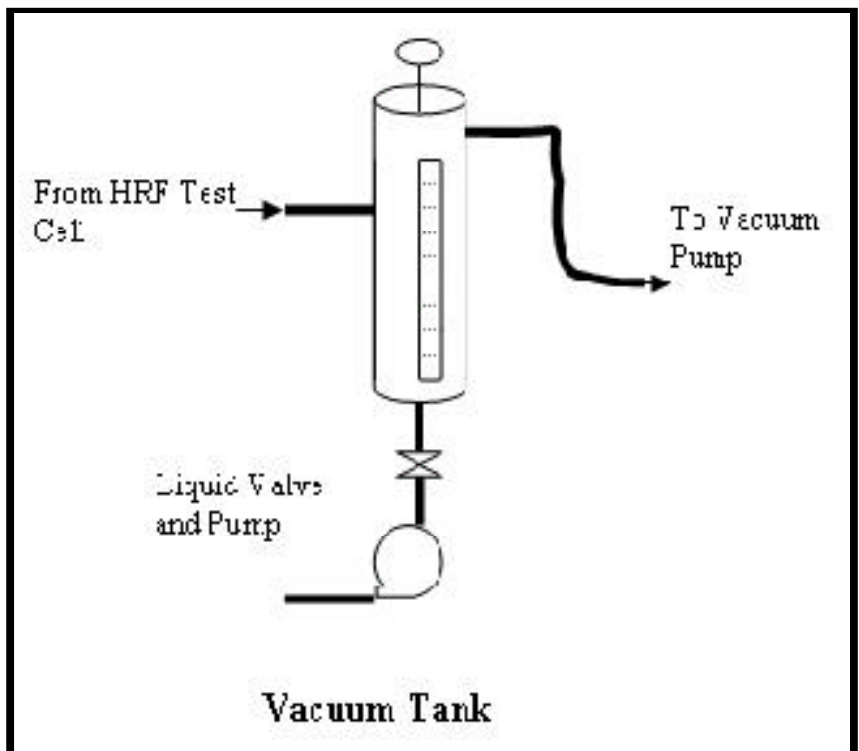

Figure 5-2. Schematics of the vacuum tank.

square by $2 \frac{1}{2}$ inches deep, lined with 10 mil( 254 micron) plastic sheeting. Fitting into one corner was a Lucite chamber with a horizontal radius of 3 inches $(7.6 \mathrm{~cm})$ and a depth of $2 \frac{1}{2}$ inches $(6.4 \mathrm{~cm})$, representing one quadrant of a 6-inch $(15 \mathrm{~cm})$ diameter well. The 90-degree outer circumference was covered by a $1 / 2$-inch by $1 / 2$-inch $(1.3 \mathrm{~cm})$ hardware cloth supporting a sheet of fine-weave polyester fabric at the outer surface. At a radius of 26 inches $(66 \mathrm{~cm})$ from the corner another piece of hardware cloth formed a quarter of a 52-inch diameter $(132 \mathrm{~cm})$ cylinder, also supporting at its inner surface another sheet of fine-weave polyester fabric. This was supported radially by three radial pieces of wood extending to the outer sides of the box. The space between the 3-inch and 26-inch radii was filled to a depth of $2 \frac{1}{2}$ inches with glass beads, having a range of diameters of 50-70 US Sieve (297-210 microns), representing porous media. The space beyond the 26-inch radius was filled with pea gravel to evenly distribute the fluid under test. A plastic sheet covers the surface above the glass beads and pea gravel. The top surface of the glass beads was leveled as well as possible, and a vacuum held the plastic in tight contact with the beads. Connections for mercury manometers were located within the Lucite chamber and the wooden box in the corner and at radii of $3,4.5,7,12$, and 21 inches (7.6, 11.4, 17.8, and $30.5 \mathrm{~cm}$, respectively).

The top of the Lucite box at the corner, representing a quadrant of the extraction well, was fitted with a pipe and flow-control valve leading to a vacuum tank. At the opposite corner was a connection to a taper-tube flow meter when testing with air, or a U-tube trap in which water could be introduced without admitting air.

Flexible tubing connected the flow-control valve to a vacuum tank 14 inches in diameter (35.6 $\mathrm{cm})$ and 72 inches $(182.9 \mathrm{~cm})$ high, Figure 5-2. A sight glass indicated depth of liquid in the tank and was calibrated in liters. One liter was represented by a depth of about one centimeter. A vacuum pump with a capacity of about $20 \mathrm{cfm}\left(0.57 \mathrm{~m}^{3} / \mathrm{min}\right)$ at a vacuum of about half an atmosphere kept 


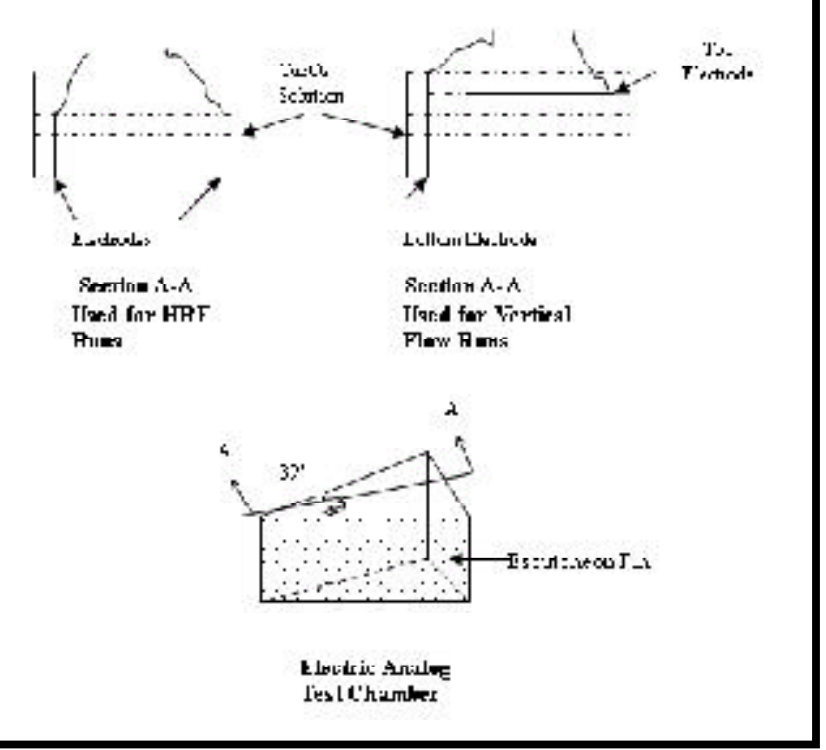

Figure 5-3. Schematics of the analog test chamber.

the tank at a nearly constant vacuum. A valve and liquid pump at the bottom of the tank removed accumulated liquids.

An aneroid barometer was used to measure atmospheric pressure, typically about $28.8 \mathrm{in}$. $\mathrm{Hg}$. A mercury thermometer measured air or water temperature, usually about $65^{\circ} \mathrm{F}\left(18^{\circ} \mathrm{C}\right)$.

Tests with air were performed before tests with water to ensure dry porous media without residual deposited solids from the water. The vacuum tank was evacuated to about half an atmosphere, then the flow control valve was slowly opened to allow a low rate of flow. The flow rate was measured by the taper-tube flow meter and levels in the manometers were recorded. The flow meter was calibrated in SCFM and was at atmospheric pressure. A small correction was made for the fact that the atmospheric pressure was less than 29.92 in.Hg. No correction was made for temperature because it was close to $70^{\circ} \mathrm{F}\left(21^{\circ} \mathrm{C}\right)$. A series of tests was made with increasing flow rates and increasing vacuum at the extraction tube. To check repeatability, series of tests were made on different days.

Water tests were performed in a similar manner. Water was used as a working fluid for the liquid tests, instead of a hydrocarbon fluid, such as diesel or jet fuel. The purpose of this substitution was to avoid fire hazard in the laboratory and to minimize any permanent contamination of the glass beads. The effect of difference in viscosity of water and hydrocarbon can be accommodated in the theoretical equations presented in the section Theory and Development of Equations.

\section{b. Permeability Test Column}

The 1-D permeability test column was used to independently measure the glass bead-packing permeability. This test column was a horizontal Lucite tube with an inside diameter of 1.5 inches (3.8 $\mathrm{cm})$. Glass beads filled in a 14-inch $(35.6 \mathrm{~cm})$ section and were retained by a fine-mesh copper screen at each end. Manometer connections were made at the free ends. One end of the column was connected via a flow-control valve to the vacuum tank described above. 


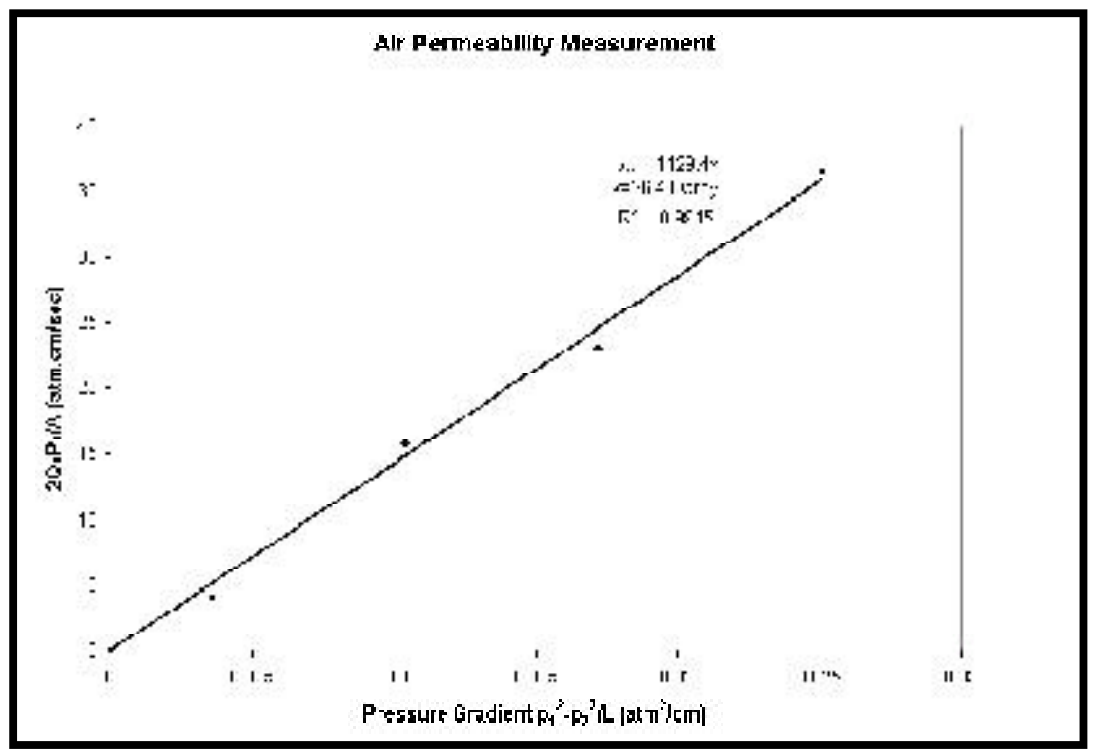

Figure 6. Air permeability measurement of the test column.

Air flow was measured by a positive displacement device. As with the tests in the HRF test cell, tests in the permeability test column began with air and then water, with low flow rates and increasing to the maximum. Tests were also repeated to evaluate repeatability.

\section{c. The Electric Analog Model for 3-D Flow Model}

A test chamber tank, shaped like a horizontal isosceles triangle, was made of masonite (90 $\mathrm{cm}$ long with a base of $59 \mathrm{~cm}$ ) as shown in Figure 5-3. The inside was made waterproof with shellac. Brass escutcheon pins were driven from inside to the outside from the apex. These pins served as electric contacts with copper-sulfate solution in the tank. For the horizontal radial flow test, a vertical copper electrode (36 gage) covered the base of the triangle and another was located at a radius of $2.3 \mathrm{~cm}$ from the apex. Copper-sulfate solution covered the floor of the tank to a depth of $6.5 \mathrm{~cm}$. For vertical-flow tests, a horizontal copper electrode at $25.4 \mathrm{~cm}$ above the bottom simulated the ground surface, and at the apex a vertical insulated wire (the second electrode) simulated the extraction well. For one test, the bottom one inch was stripped and for the second test the bottom two inches were stripped, simulating the perforated section of a well. The tank was filled with copper-sulfate solution until it covered the top electrode.

A resistivity cell (shown in Figure 5-3) consisted of a masonite tank $25 \mathrm{~cm}$ long, $4.5 \mathrm{~cm}$ wide and $8 \mathrm{~cm}$ deep, shellaced on the inside. Copper electrodes covered both ends of the tank. Copper sulfate solution from the horizontal and vertical-flow tests filled the cell to a depth of $6.5 \mathrm{~cm}$. Resistivity test were made individually for the horizontal and vertical tests, respectively. The resistivity was calculated based on measured current and voltage, using a 12.5-volt or 9.0-volt battery as power supply. 


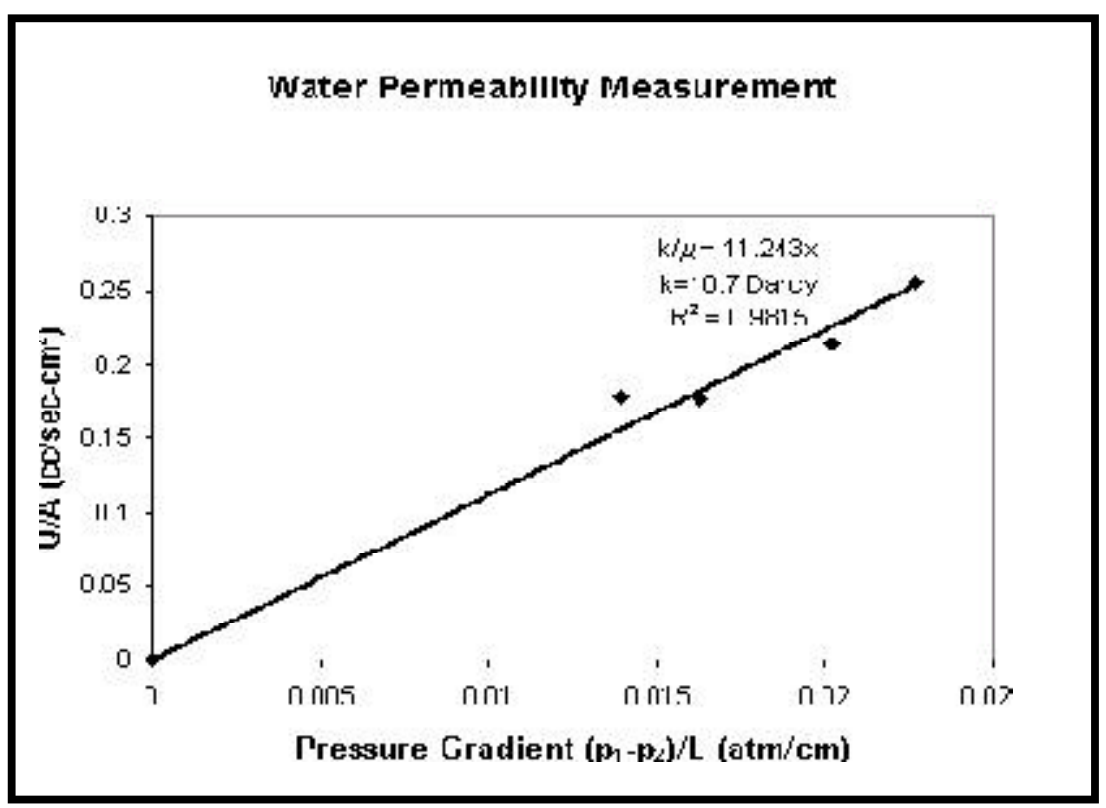

Figure 7. Water permeability measurement of the test column.

TEST RESULTS

\section{a. Permeability Measurements on the Test Column}

1) Air

Air permeability tests consisted of four runs at different flow rates and pressure differentials. The air temperature was $22^{\circ} \mathrm{C}$, and the barometric pressure was 28.85 inches of $\mathrm{Hg}(0.964 \mathrm{~atm})$. The Darcy equation was modified to account for variations in specific volume with pressure as discussed (section Air in Porous Medium - Pressure Driven), integrated, and solved for the ratio of permeability to viscosity as shown below. Several flow measurements were made for each pressure differential, and results are plotted in Figure 6. $\quad$.

$$
\begin{gathered}
\frac{\dot{m} R T}{p A}=-\frac{k}{\mu} \frac{d p}{d x} \\
\left.\frac{p^{2}}{2}\right|_{p_{2}} ^{p_{2}}=-\left.\frac{\dot{m} R T}{A} \frac{\mu}{k} x\right|_{0} ^{L} \\
\frac{k}{\mu}=\left(\frac{2 Q_{1} p_{1}}{A}\right) \frac{L}{p_{1}^{2}-p_{2}^{2}}
\end{gathered}
$$

With an air vicosity of $0.0185 \mathrm{cp}$, the air permeability was obtained form the slope $(\mathrm{k} / \mu=1429.1)$ of the best-fit straight line through the origin to be 26.4 Darcy.

\section{2) Water}

Water permeability tests were measured on the permeability test column. With a water viscosity of $0.955 \mathrm{cp}$, the permeability was obtained from the slope $(\mathrm{k} / \mu=11.243)$ of the best straight-line fit (plotted in Figure 7) to be 10.7 Darcy. 


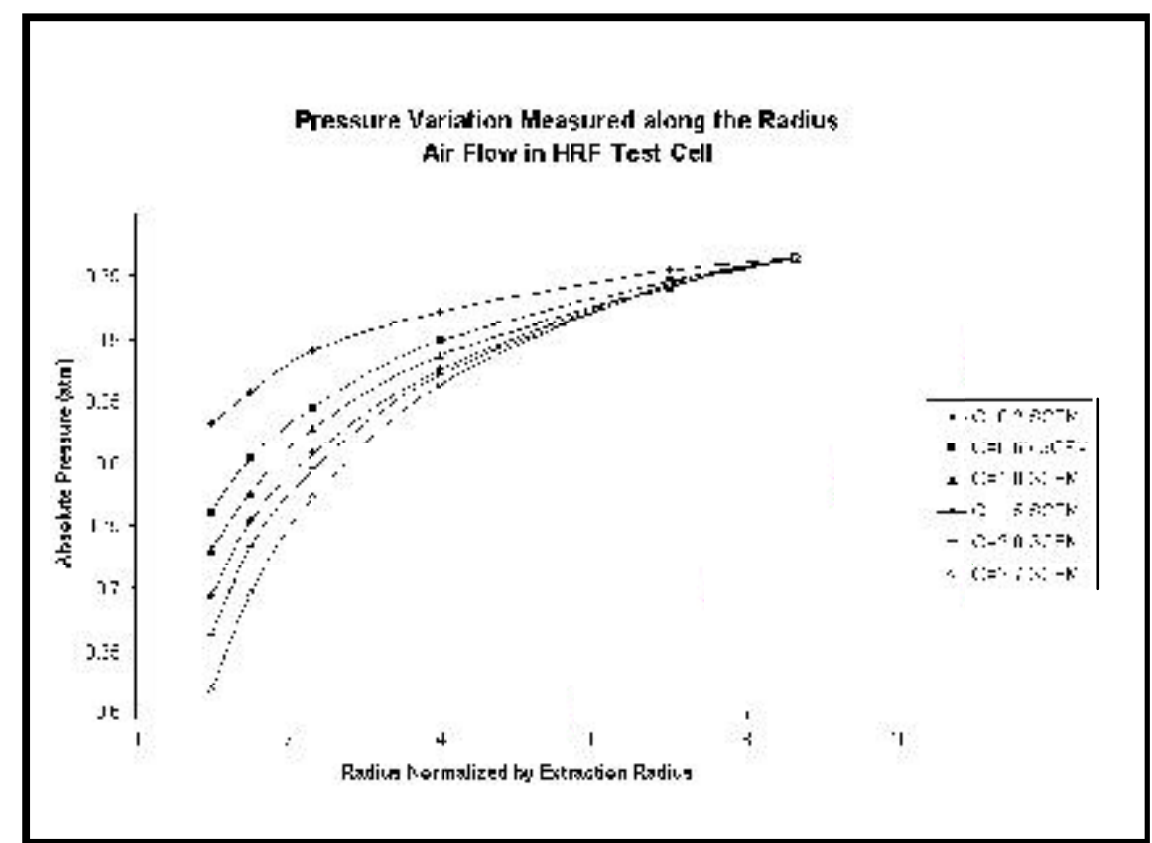

Figure 8. Pressure variation vs. radius-air flow (HRF test cell).

\section{b. HRF Test Cell}

\section{1) Test Cell Air Measurements}

A representative set of measurements with air on the HRF test cell, ranging from $0.2-2.7$ SCFM flow rates, is shown in Figure 8. The data points on the curves correspond to the six pressure stations, at radii of $3,4.5,7,12,21$, and 26 inches, normalized by the extraction radius of 3 in. $(1,1.5,2.33,4,7$, and 8.67 respectively). Station 0 is at the extraction tube or wall and pressure at Station 5, radius $26 \mathrm{in}$., is assumed to be the barometric pressure $(0.963 \mathrm{~atm})$. The flow rates were read as CFM from a taper-tube flow meter and corrected to SCFM (29.92 in. $\mathrm{Hg}, 70^{\circ} \mathrm{F}$ ). The experimental mass-flow rate for one quadrant was multiplied by four so that it could be compared with the theoretical values. The correction factor for barometric pressures of 28.78 and 28.84 in. $\mathrm{Hg}$ was 0.98 . No correction for temperatures was required. In general, the family of curves behaved similarly. Equation 17 shows that mass flow rate, $\dot{m}$ was proportional to $\left(\mathrm{p}^{2}-\mathrm{p}_{\mathrm{w}}{ }^{2}\right)$ as a test of integrity of the data.

Figure 9 is a plot of measured air-flow data. A smooth curve through the six plotted points does not indicate a straight-line relation. However, if the curve is extended from the lowest plotted point to zero-zero, the extension appears to be a straight line. This suggests that the plotted points lie in the region of turbulent flow, whereas the straight-line extension would be in the viscous (laminar) region on which Equation 18 is based.

$$
\left(p_{5}^{2}-p_{w}^{2}\right)=\frac{\dot{m} R T}{\pi t} \frac{k}{\mu} \ln \frac{r_{5}}{r_{w}}
$$




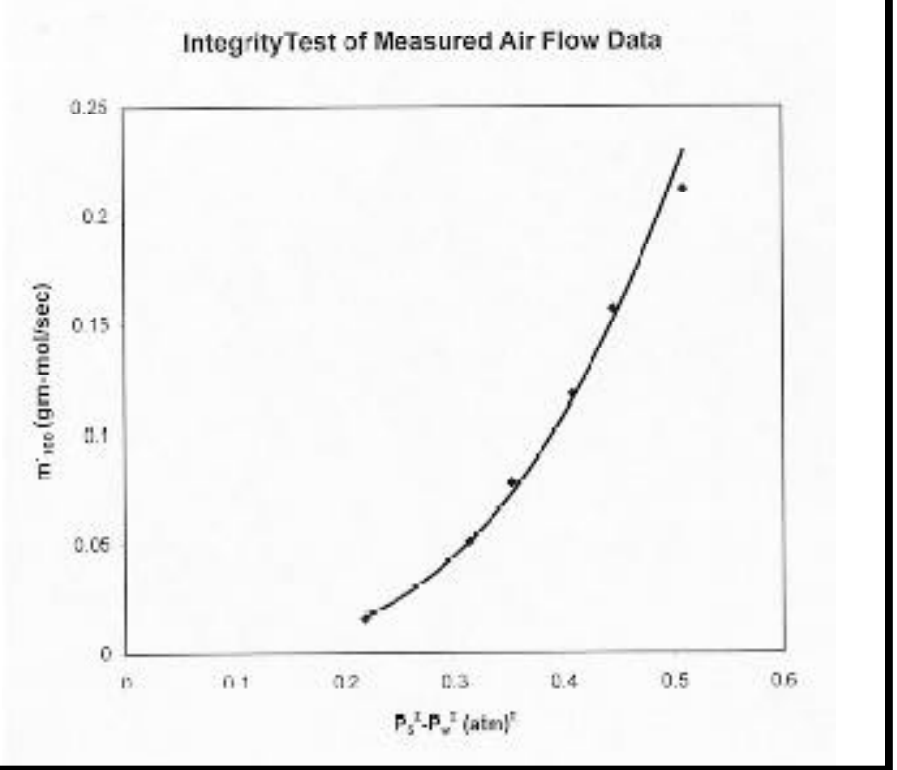

Figure 9. Integrity test of air flow data.

\section{2) Test Cell Water Measurements}

The test cell was first saturated with water while vacuum was applied to remove all trapped air. Then measurements with water were conducted by applying vacuum to a saturated test cell, while flow rate and pressure drops at each station were recorded. A total of ten runs, on two different days, were done. We had some difficulty reading manometers at Stations 4 and 5 when pressures were less than 5/16 of inch $\mathrm{Hg}$. Since these stations were remote from the extraction well and the pressures were close to atmospheric, their exact values are of minor interest as compared to pressure closer to the well-Stations 2 and 3. Figure 10 shows pressures plotted against radii from the center of the extraction tube. The plotted points for Stations 1 and 2 in some of the curves show some scatter. Use of inclined manometers or high-accuracy digital manometers could improve measurement inaccuracies.

Equation 15, in section Liquid in Porous Medium-Pressure Driven, shows flow rate, Q, is proportional to $\left(\mathrm{P}-\mathrm{P}_{\mathrm{w}}\right)$. Figure 11 shows the straight-line relation between $\mathrm{Q}$ and $\left(\mathrm{P}_{5}-\mathrm{P}_{\mathrm{w}}\right)$. While there is some scatter of plotted points, a straight-line relation is evident.

$$
Q=\frac{\frac{2 \pi t k}{\mu}}{\ln \frac{r}{r_{w}}}\left(p-p_{w}\right)
$$

Repeatability of test cell measurements for air was good and for water it was poor.

\section{3) Comparison of Measurements on HRF Test Cell with Theory}

Test results and theory can be compared in several ways. They can be compared by plotting theoretical pressure vs. radius curves similar to Figures 8 and 10 for air and water, respectively, 


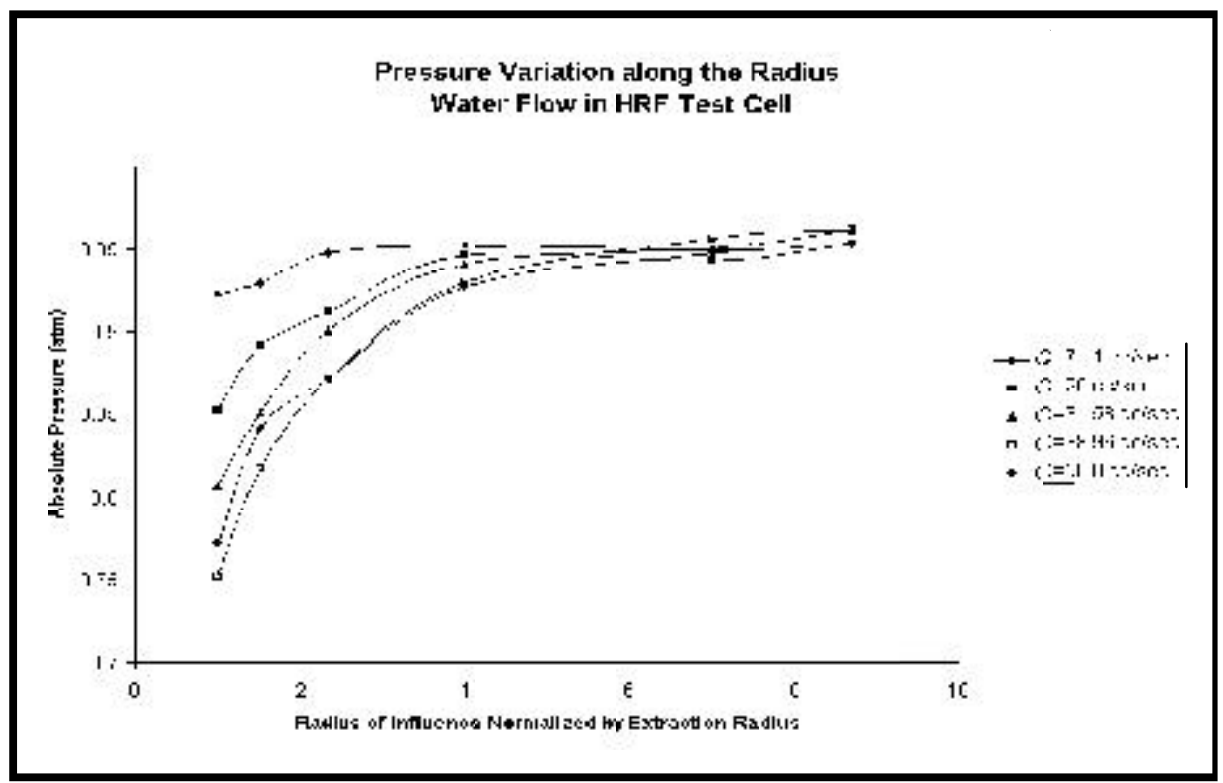

Figure 10. Pressure variation vs. radius — water flow (HRF Test Cell).

using the same flow rates, $\dot{m}$ and $\mathrm{Q}$, and permeabilities, $k$, from the permeability column tests, 26.9 Darcy for air and 10.7 Darcy for water. Figure 12 shows these comparisons at a flow rate of 5.2 and 10.0 SCFM $\left(\mathrm{Q}_{360}\right)$ for air, and Figure 13 shows comparisons at flow rates of 28.6 and 200 $\mathrm{cc} / \mathrm{sec}\left(\mathrm{Q}_{360}\right)$ for water. It is evident that, while the curves are similar for theory and test, there is a significant difference in magnitude. In the case of air, the tested pressure gradients were steeper than the theoretical gradients. This suggested that the permeability in the test cell was less than the permeability, 26.4 Darcy, used in the theoretical calculations. In the case of water tests, the tested gradients were less than the theoretical, suggesting that permeability during tests was greater than the permeability, 10.7 Darcys, used in the theoretical calculations.

To evaluate this possibility, the permeabilities required to produce these test data were calculated. For the two air runs presented in Figure 12, permeabilities in the HRF test cell were calculated as 17.6 and 15.0 Darcys, or an average of 16.3 Darcys, as compared with 26.4 Darcys measured in the permeability test column. For the two water tests in the HRF test cell presented in Figure 13, the calculated permeabilities were 56.8 and 47.7 Darcys with an average of 52.3 Darcys, as compared with 10.7 Darcys measured in the test column.

For air, the lower computed permeability (16.3 vs. 26.4) in the HRF test cell could be attributed to more tightly packing of the grains in the HRF test cell than in the permeability test column. Although the HRF test cell and the permeability test column used glass beads from the same source and batch, it is possible that they were not compacted to the same density. It is conceivable since the beads were not of uniform diameter (see section Horizontal Radial Flow Test Cell) that the actual size distribution was not the same in the HRF test cell and in the permeability test column. On the other hand, for water, the dramatic increase of permeability in the HRF test cell (52.3 vs. 10.7) 


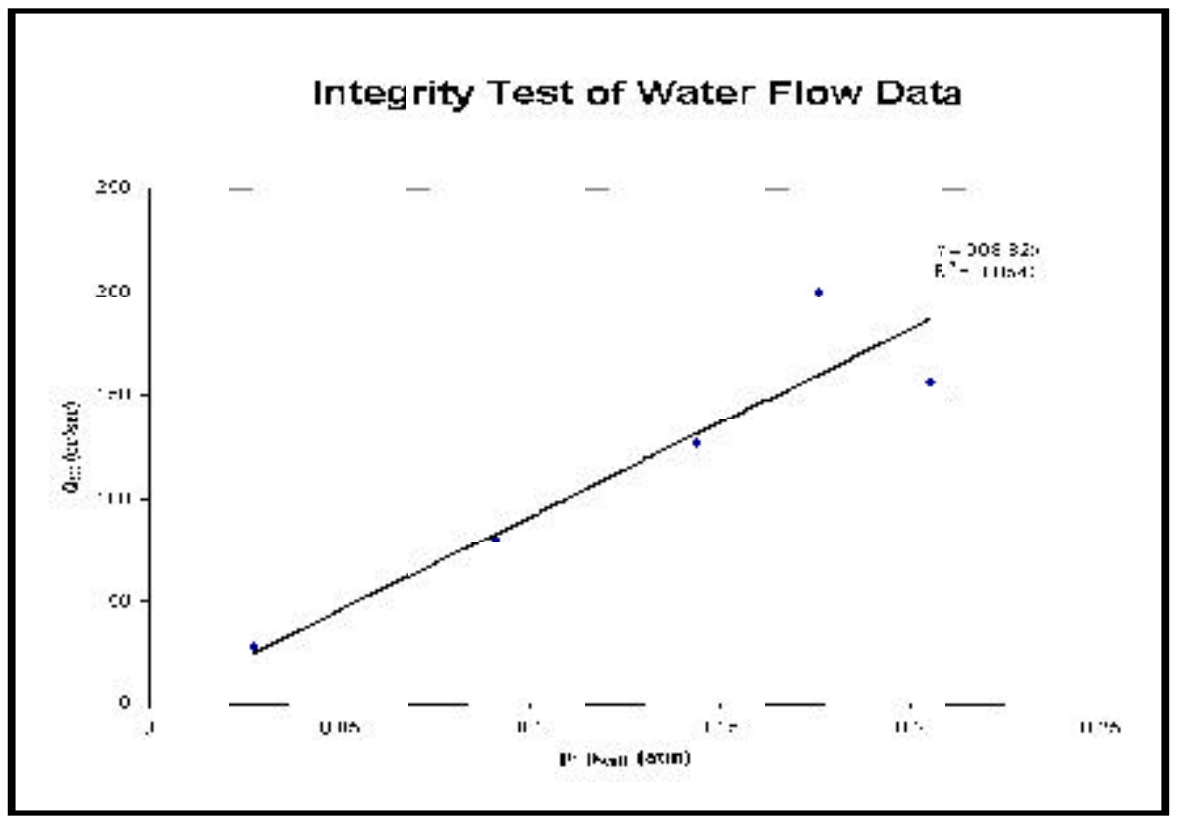

Figure 11. Integrity test of water flow data.

suggests that somehow water was bypassing the packed beads to allow a large flow with small pressure gradient. We also observed some glass bead flow during the water tests. This could have also caused the larger permeability in the HRF test cell. These experimental difficulties should be eliminated in future measurements.

Based on the comparison between the derived theoretical equations and the laboratory measurement, we can conclude that theory can provide a good indication of test results provided that the permeability used for the theoretical calculations is the same as that used in the test cell.

\section{c. Measurement Results on the Electric Analog Model}

The measured voltage distribution for the electric analog of the horizontal radial model agreed well with the calculated and measured pressure distribution in the horizontal radial-fluid flow in porous media. This indicated that the electrical model was a good analog for fluid flow.

The combined vertical and horizontal voltage distribution in the electric model was analogous to a 3-D flow model. Two tests were performed to determine voltage distribution as a function of radius and distance from the top surface. Electric flow patterns were perpendicular to lines of constant voltage, and voltage gradients were proportional to current flow per unit area, i.e., amps/ $\mathrm{cm}^{2}$. As noted in the section Test Equipment and Procedure, the top electrode was a horizontal copper foil at 25.4 inches above the bottom of the test chamber, representing the ground surface. An insulated copper wire was mounted vertically at the apex of the tank. Two tests were performed, where the bottom $2.54 \mathrm{~cm}$ and $5 \mathrm{~cm}$ of the copper wire were stripped of insulation to represent $10 \%$ and $20 \%$ perforations. The maximum radius from the apex of the tank was about three times the depth. The tank was filled with copper-sulfate solution, whose resistivity was measured independently. As expected, the voltage gradients, and hence the current densities, were 


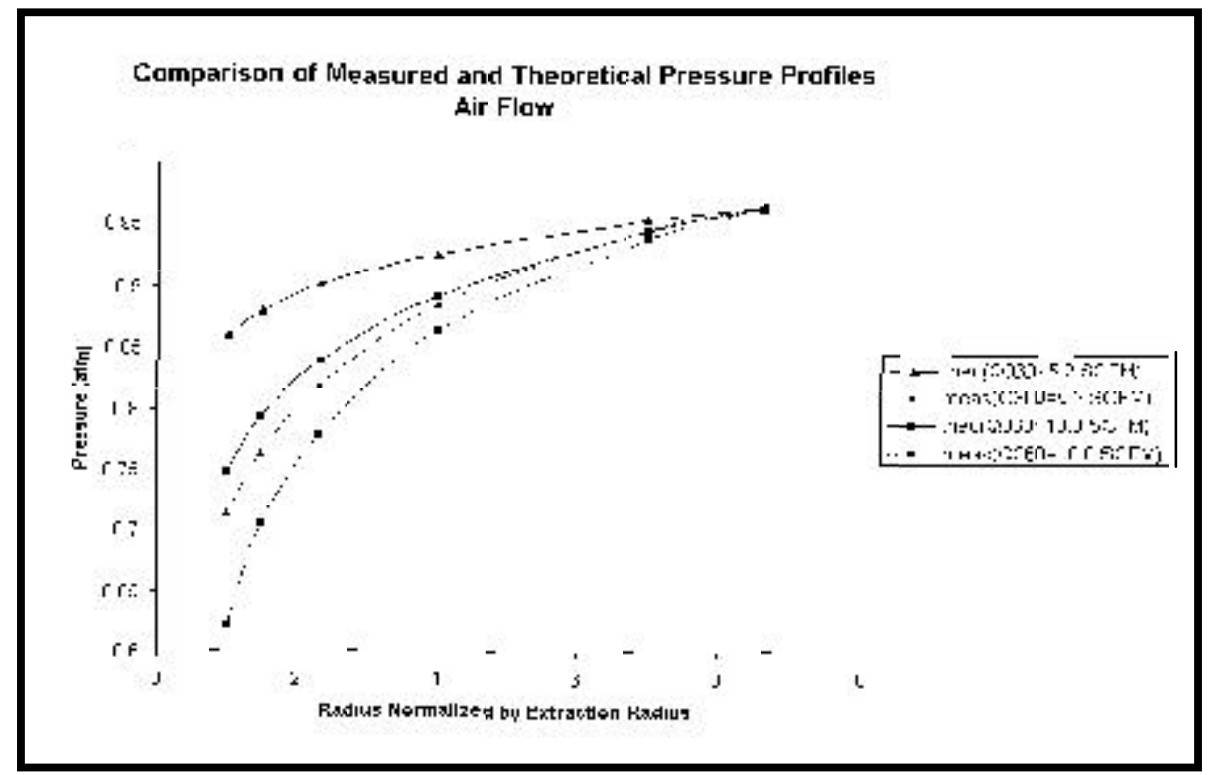

Figure 12. Comparison of measured and theoretical pressure-air flow.

high in the vicinity of the vertical electrode. Also, voltage gradients and current densities at the surface were highest at small radii and very low at radii of 1 to $1 \frac{1}{2}$-half times the depth of the tank, where the voltage difference dropped to zero volts. The radius of influence of the electric analog, i.e., where the voltage was that of the top electrode, appeared to extend to a radius of about 1.5 times the depth. This suggests that a 3-D fluid model should have a radius of at least 1.5 times the depth to ensure that the radius of the model exceeds the radius of influence. Presumably this would apply to a laboratory fluid model or to a full-scale bioslurping system.

\section{CONCLUSIONS}

a. There was good agreement between theoretical and test results in the form of pressure vs. radius curves (section HRF Test Cell), but the theoretical and test results differed significantly in the magnitude of the pressure gradients. In the case of the air tests, the difference seemed attributable to differences in permeabilities of the test column and the HRF test cell. In the case of water tests, the high permeability found in the HRF test cell compared to that in the permeability test column seemed to be attributable to water somehow bypassing the porous medium of the HRF test cell. It is concluded that some deficiency in the test equipment or procedure might contribute to these problems. In section Measurement Results on the Electric Analog Model, it was noted that the plotted experimental points did not verify the straight-line relation between mand $\left(\mathrm{P}_{5}{ }^{2}-\mathrm{p}_{\mathrm{w}}{ }^{2}\right)$. It is concluded that the experiment was actually conducted in the turbulent regime of flow rather than in the viscous (laminar) regime, as intended. However, the straight line from zero-zero to the lowest plotted point would validate the straight-line relation of Equation 18.

It is possible that some of the problems may relate to mobility of the glass beads. It is concluded that some of the problems might be eliminated, or at least reduced, if the beads could be 


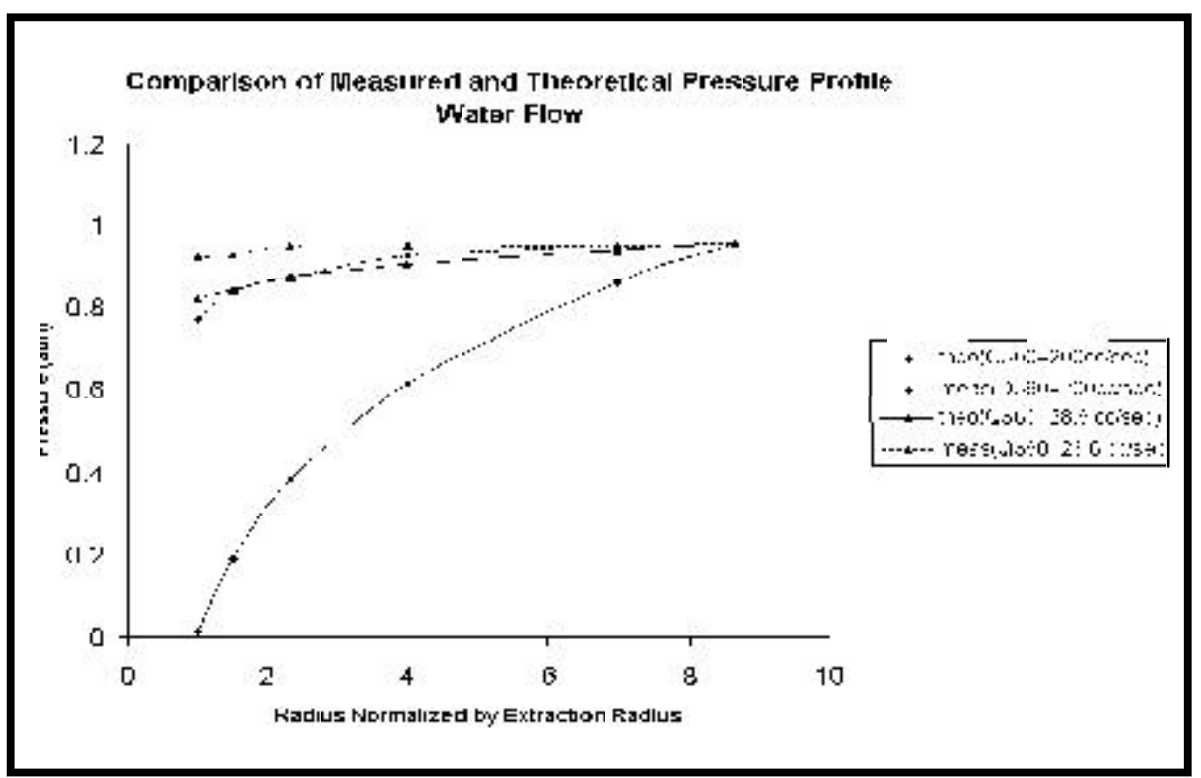

Figure 13. Comparison of measured and theoretical pressure-water flow.

assembled into a solid porous mass, such as by sintering or cementing. Another possibility would be to assemble the porous mass from layers of cloth, felt, or other fibrous material.

b. It is concluded that, in spite of experimental problems of the project, the theory can be the basis for additional analysis and experiments involving two-phased and 3-D flow. These would become the basis for analysis and design of a full-scale system and prediction of its performance. This conclusion is valid only to the extent that the theory reflects the actual site conditions. The theory of this project was based on horizontal-radial flow in a porous medium, bound top and bottom by impervious layers. The theory would have to be modified to reflect the possibility of vertical components of flow and of non-uniformity of the porous medium.

c. In an actual bioslurping well, the flow of liquid would be primarily horizontal and radial and approximately predictable by the theory developed above. On the other hand, the flow of air would be primarily vertical from the surface to the well. This has not been addressed theoretically or experimentally, but would be the next step in this program.

\section{RECOMMENDATIONS}

a. For any future tests, equipment design and test procedures should address the problems encountered on this project. (The problems were not evident until test results were analyzed.) These problems include the following:

1) Mobility of grains comprising the porous medium and the possibility of non-uniformity of permeability.

2) Possibility of fluid bypassing the porous medium as it flows toward the extraction well.

3) Discrepancy between the experimental data of Figure 9 and Equation 17 suggests that the experiments were performed in the turbulent region of flow rather than the viscous regime. Future experiments 
should include low-volume flows with small pressure drops, to ensure that at least part of the experiment is in the viscous regime, corresponding to flow in typical field applications.

b. A next step in the overall program, would be to investigate theoretically and experimentally the flow of air from the surface to the well. This would involve three-dimensional flow with a very large vertical component.

c. Bioslurping involves a combined flow of air and liquid, especially near the well. It is probable that the pressure gradients of the air in contact with the liquid would influence liquid-flow patterns and vice versa. It is recommended that this be investigated theoretically and experimentally, and involve the theory and test techniques developed in this project and the air-flow project recommended above.

\section{APPENDIX}

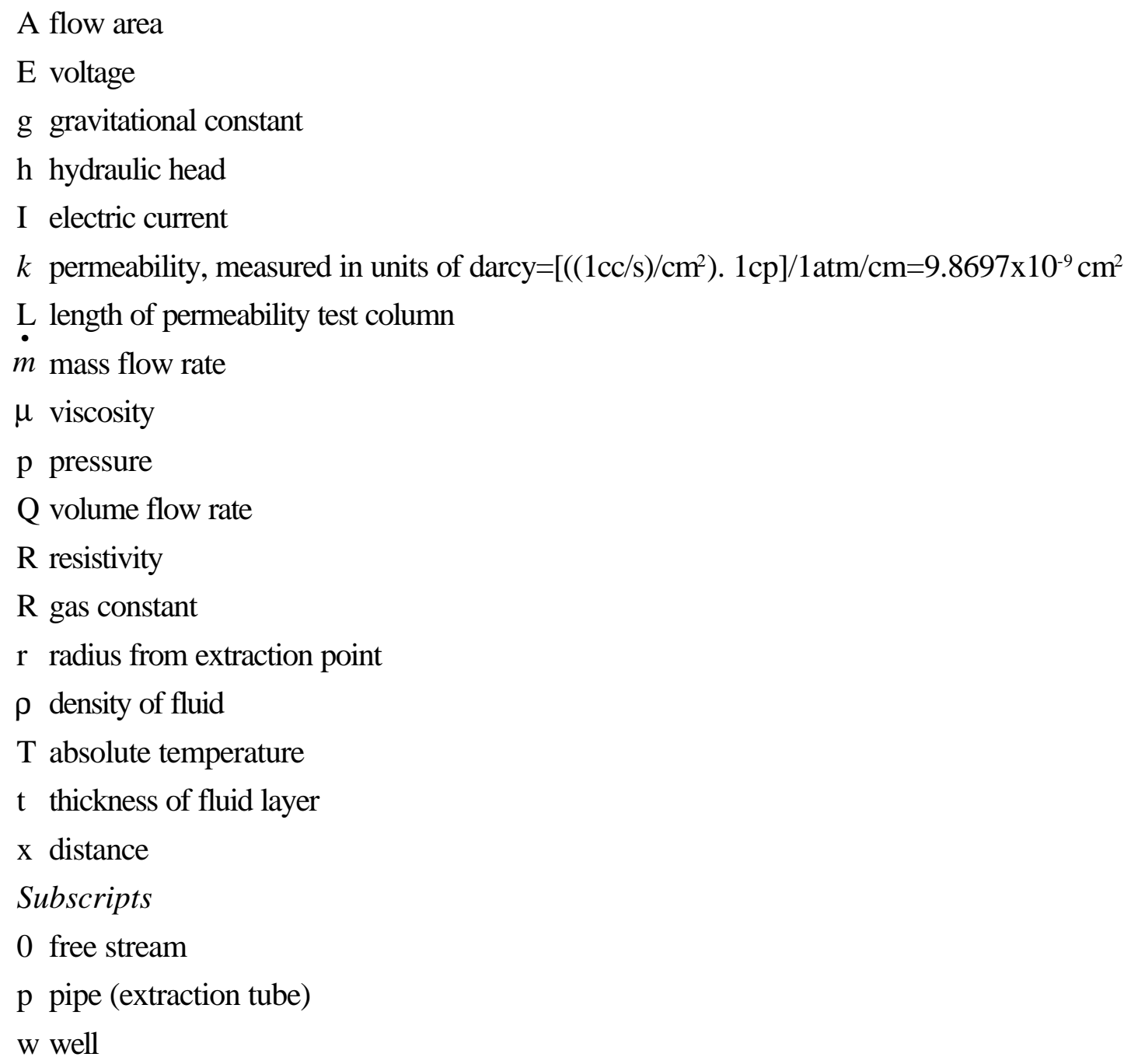




\section{REFERENCES}

DeVantier, B., and R.E. Hoeppel, 1996. Flow Modeling for Vacuum-Assisted Free LNAPL Removal, A.K.A. Bioslurping. Proceedings of IASTED, International Conference on Advanced Technology in the Environmental Field, Gold Coast, Australia, May 7-9.

Hoeppel, R.E., R.E Hinchee, and M.F.Arthur, 1991. Bioventing Soils Contaminated with Petroleum Hydrocarbons. J. Industrial Microbiology, 8,141-146.

Kittel, J.A., R.E Hoeppel, R.E Hinchee, T.C. Zwick, and R.J. Watts, 1994. In situ Remediation of Low-Volatility Fuels Using Bioventing Technology. Hydrocarbon Contaminated Soils, Volume IV, ASP, Amherst, Massachusetts.

Hoeppel, R.E., F. Goetz, J.A. Kittel, M. Place, and S. S. Di Julio, 1996. Bioslurping: Combined Vacuum-Enhanced, Free-Fuel Removal and Bioventing. Proc. $12^{\text {th }}$ Annual Environmental Management and Technology Conference West, Long Beach, CA.

Hoeppel, R.E., C. Tanwir, M. Kelley, and M. Place, 1999. Current Fuel and Chlorinated-Solvent Remediation: Bioslurping Free Product and Monitored Natural Attenuation of the Soluble Plume. Remediation of Hazardous Waste Contaminated Soils, $2^{\text {nd }}$ Edition, Marcel Dekker, Inc.

Original Manuscript Received: June 6, 2001

Revised Manuscript Received: September 15, 2001 